\title{
Estimating snow depth over Arctic sea ice from calibrated dual-frequency radar freeboards
}

\author{
Isobel R. Lawrence ${ }^{1}$, Michel C. Tsamados ${ }^{1}$, Julienne C. Stroeve ${ }^{1,2}$, Thomas W. K. Armitage ${ }^{3}$, and Andy L. Ridout ${ }^{1}$ \\ ${ }^{1}$ Centre for Polar Observation and Modelling, Earth Sciences, University College London, London, UK \\ ${ }^{2}$ National Snow and Ice Data Center, University of Colorado, Boulder, CO, USA \\ ${ }^{3}$ Jet Propulsion Laboratory, California Institute of Technology, Pasadena, CA, USA
}

Correspondence: Isobel R. Lawrence (isobel.lawrence.15@ucl.ac.uk)

Received: 11 March 2018 - Discussion started: 29 March 2018

Revised: 15 August 2018 - Accepted: 25 October 2018 - Published: 13 November 2018

\begin{abstract}
Snow depth on sea ice remains one of the largest uncertainties in sea ice thickness retrievals from satellite altimetry. Here we outline an approach for deriving snow depth that can be applied to any coincident freeboard measurements after calibration with independent observations of snow and ice freeboard. Freeboard estimates from CryoSat-2 (Ku band) and AltiKa (Ka band) are calibrated against data from NASA's Operation IceBridge (OIB) to align AltiKa with the snow surface and CryoSat-2 with the ice-snow interface. Snow depth is found as the difference between the two calibrated freeboards, with a correction added for the slower speed of light propagation through snow. We perform an initial evaluation of our derived snow depth product against OIB snow depth data by excluding successive years of OIB data from the analysis. We find a root-mean-square deviation of $7.7,5.3,5.9$, and $6.7 \mathrm{~cm}$ between our snow thickness product and OIB data from the springs of 2013, 2014, 2015, and 2016 respectively. We further demonstrate the applicability of the method to ICESat and Envisat, offering promising potential for the application to CryoSat-2 and ICESat-2, which launched in September 2018.
\end{abstract}

\section{Introduction}

The addition of snow on sea ice, given its optical and thermal properties, generates several effects on the climate of the polar regions. Owing to its large air content, snow has a thermal conductivity 10 times less than that of ice (Maykut and Untersteiner, 1971). During the winter freeze-up, it forms an insulating layer that reduces heat flow from the ocean to the atmosphere and slows the rate at which seawater freezes to the bottom of the ice, dampening further ice growth (Sturm et al., 2002).

Snow has an optical albedo in the range of $0.7-0.85$, compared to 0.6-0.65 for melting white ice (Grenfell and Maykut, 1977). At the onset of the melt season, short-wave solar radiation is reflected from the surface, limiting ice melt. These properties make snow on sea ice important in energy budget considerations, and the inclusion of accurate Arctic snow depth estimates would improve current weather and sea ice forecasting (Stroeve et al., 2018).

As well as its climatic importance, snow depth plays a key role in the retrieval of sea ice thickness from satellite altimetry. Over the past 2 decades both radar (e.g. ERS-2, Envisat, CryoSat-2) and laser (e.g. ICESat) altimeters have enabled sea ice thickness to be retrieved from space, first by measuring the sea ice freeboard (the portion of the ice floe above the water), and then converting this to thickness by assuming that the floe is in hydrostatic equilibrium with the surrounding ocean (Laxon et al., 2003; Giles et al., 2008; Laxon et al., 2013; Kwok and Cunningham, 2008). For both the radar and laser cases, snow depth is one of the dominant sources of sea ice thickness uncertainty (Giles et al., 2007; Ricker et al., 2014; Tilling et al., 2018; Zygmuntowska et al., 2014).

In situ measurements of snow depth and density for the 37year span from 1954-1991 provided the first comprehensive Arctic snow climatology. The data set, compiled and published by Warren et al. (1999), comprises of measurements gathered at Soviet drifting stations across the central Arctic. Stations were located over multi-year ice, which at the time of data collection spanned an area of some $7 \times 10^{6} \mathrm{~km}^{2}$. Re- 
cent studies have demonstrated that the Arctic is undergoing a transition from multi-year to first-year ice (Comiso, 2012), and the inaccuracy of the Warren climatology over seasonal ice has been emphasised by a number of studies (Kurtz and Farrell, 2011; Kurtz et al., 2013; Webster et al., 2014; Kern et al., 2015).

Despite only representing historical conditions, the Warren climatology remains the choice source of Arctic-wide snow depth estimates used in the processing of contemporary sea ice thickness, i.e. from CryoSat-2 (hereafter CS-2, a Kuband radar satellite altimeter operational since 2010). In order to address the change to a more seasonal ice regime, Warren snow depths are halved over first-year ice regions to accommodate the lesser accumulation they experience (Ricker et al., 2014; Guerreiro et al., 2017; Tilling et al., 2018; Kurtz et al., 2014). Although this modification generates temporal and spatial variability of snow depths due to the changing multi-year ice fraction, trends in precipitation and accumulation are not accounted for, rendering time series analyses of snow depths impossible by this method.

Only satellite-derived snow depth estimates can offer the spatio-temporal resolution required for time series analysis and accurate monthly sea ice thickness derivation, but retrieving snow depth from space has proven challenging and is an ongoing effort for the sea ice community. Existing methods have historically relied on using relationships between passive microwave brightness temperatures and snow thickness. Using data over Antarctic sea ice from the Defense Meteorological Satellite Program (DMSP) special sensor microwave/imager (SSM/I), Markus and Cavalieri (1998) compared the spectral gradient ratio of the 19 and $37 \mathrm{GHz}$ vertical polarisation channels with in situ snow depth data in order to express snow depth as a function of brightness temperature. The algorithm was later developed for application to Arctic sea ice using data from the Advanced Microwave Scanning Radiometer-EOS (AMSR-E), but due to the inability to distinguish signatures from snow and multi-year ice, the available AMSR-E data product is limited to seasonal ice only (Comiso et al., 2003; Markus and Cavalieri, 2012). Furthermore, subsequent studies have demonstrated the sensitivity of the retrieved snow depth to snowpack conditions and surface roughness (Stroeve et al., 2005; Powell et al., 2006).

Maaß et al. (2013) utilised a frequency of $1.4 \mathrm{GHz}$ (Lband), measured by the European Space Agency's Soil Moisture and Ocean Salinity (SMOS) satellite to retrieve snow depth. Although snow is transparent to L-band frequencies, i.e. the large wavelengths are not attenuated by the snow, their model-based study found brightness temperatures from the ice increased at L-band frequencies when a snow layer was present due to its insulating properties and the dependence of ice emissivity on temperature.

Using a radiative transfer model, they tested the impact of $0-70 \mathrm{~cm}$ varying snow thickness on L-band brightness temperatures for a number of scenarios (in which ice temperature, thickness, salinity, and snow density varied within a realistic range). The snow depth which produced a brightness temperature most comparable (smallest rootmean-square deviation and best correlation coefficient) to the SMOS brightness temperature was then compared with snow thickness from Operation IceBridge (OIB) in order to assess which scenario performed best. Snow depths produced by this scenario correlated well (root-mean-square deviation $=5.5 \mathrm{~cm}$ ) up to model-generated depths of $35 \mathrm{~cm}$, but overestimated snow depth thereafter, owing to the desensitisation of brightness temperatures when snow depth increases above $35 \mathrm{~cm}$. Furthermore, this approach requires that the values for the input parameters (ice temperature, thickness, salinity, and snow density) are assumed valid everywhere. In reality, these parameters vary in space and time, and the authors express the need to develop the methodology further to allow regional and temporal variability of model input parameters. At time of publication of this study, no SMOS snow depth product has been made publicly available.

A recent approach to snow depth retrieval from satellites was offered by Guerreiro et al. (2016), who demonstrated the potential to estimate snow thickness by comparing retrievals from coincident satellite radar altimeters operating at different frequencies. Snow depth over Arctic sea ice (up to $81.5^{\circ} \mathrm{N}$ ) was retrieved by differencing the elevation retrievals from AltiKa (Ka-band radar satellite altimeter, 2013present) and CS-2. To investigate the penetration properties of the two radar altimeters, the authors simulated penetration depth as a function of snow grain size under different temperature and density conditions, derived from the equation for the extinction coefficient of the radar signal. Based on these model simulations the authors suggested that the Ka-band signal stops within the first few centimetres of the snow, and that the Ku-band signal can be reflected before the snow-ice interface in the case of large snow grains. In the following analysis to retrieve snow depth, however, this grain-size dependence of signal penetration is essentially neglected, and it is assumed that AltiKa does not penetrate the snow at all whilst CS-2 penetrates it fully, allowing snow depth to be calculated simply as the difference between the two.

A previous study by Armitage and Ridout (2015) also compared retrievals from AltiKa and CS-2; they found a basin-mean freeboard difference of $4.4 \mathrm{~cm}$ in October 2013 increasing to $6.9 \mathrm{~cm}$ in March 2014, with AltiKa consistently higher across the basin and season. By comparing the freeboards retrieved from each satellite with ice freeboard from NASA's Operation IceBridge, radar penetration at a local grid-scale level was quantified. Under the assumption that multi-year ice and first-year ice characterise snow and ice packs with distinctive penetrative properties, an average value for the radar penetration factor was found for each satellite over each ice type. Though limited to the spring due to the availability of OIB data and therefore not necessarily representative of penetration properties throughout the year, the study highlights the importance of accounting for regional differences in penetration depth. 
Guerreiro et al. (2017) compared freeboards from Envisat, a Ku-band pulse-limited altimeter, with those from the CS-2 Synthetic Aperture Radar (SAR) system. Since both altimeters operate at the same frequency, they are expected to penetrate to the same depth and therefore retrieve comparable freeboards. The study found Envisat was biased low compared with CS-2, attributed to differences in footprint size $(0.3 \times 1.7 \mathrm{~km}$ for CS-2 vs. $2-10 \mathrm{~km}$ diameter for Envisat) and the effect of using an empirical retracker on Envisat's pulse-limited waveforms (discussed in Sect. 2.3). Schwegmann et al. (2016) performed a similar Envisat vs. CS-2 freeboard comparison over Antarctic sea ice and also found a bias on Envisat's freeboard attributed to its larger footprint.

These results suggest that the freeboard difference between AltiKa and CS-2 found in Armitage and Ridout (2015) may not have been solely the result of a difference in physical snow penetration, but due also to differences in sampling area and processing technique. AltiKa has a smaller pulselimited footprint than that of Envisat (1.4 km compared with $2-10 \mathrm{~km})$; nevertheless, we would expect the impact of its different footprint with respect to CS-2 to introduce a bias like that seen in the Envisat data. This is discussed fully in Sect. 2.3.

Based on studies of snow penetration depth as a function of microwave wavelength (Ulaby et al., 1984), we expect the CS-2 Ku-band pulse to penetrate further into the snowpack than AltiKa's Ka-band, but unlike previous studies (Guerreiro et al., 2016; Armitage and Ridout, 2015) we do not try to quantify this penetration depth. Based on the results of Guerreiro et al. (2017), Schwegmann et al. (2016), and Kurtz et al. (2014), we assume that the effects of snow penetration and biases due to sampling area cannot be separated and instead correct for both simultaneously by calibrating satellite freeboards with independent freeboard data. We make use of snow depth and laser freeboard data from OIB to assess the deviation of AltiKa and CS-2 satellite freeboards from the snow surface and snow-ice interface respectively. We assume this deviation to result from the combination of competing effects; snow penetration, biases due to sampling area and surface roughness, and the effect of the threshold retracker on the satellite waveforms. Like Guerreiro et al. (2017), we use satellite pulse peakiness (PP) as a characterisation of the surface and compare each satellite's deviation from its expected dominant scattering horizon $(\Delta f)$ against PP. Using the relationships between $\Delta f$ and PP, we then calibrate both AltiKa and CS-2 freeboards to bring them in line with the snow surface and snow-ice interface respectively. Finally we estimate dual-altimeter snow thickness (DuST) as the difference between the calibrated AltiKa and CS-2 freeboards.

In the next section we outline the data sets used and discuss why the properties of the area sampled by the satellite footprint can create a bias on freeboard which is inseparable from the physical snow penetration of the signal. In Sect. 2.5 and 2.6 we calibrate the AltiKa and CS-2 freeboards and then present the results of this calibration applied to the 20152016 growth season and discuss the retrieved snow depth estimates with reference to large-scale weather phenomena in Sect. 3.1. We provide an analysis of the uncertainty on our gridded DuST product and compare it with OIB snow depth data not included in the calibration in Sect. 3.2. Finally in Sect. 3.4, we apply the DuST methodology to freeboards from the ICESat and Envisat satellites.

\section{Data and methods}

\subsection{AltiKa}

The SARAL/AltiKa satellite (herein referred to as AltiKa), was launched in spring 2013 as a joint mission between the Centre National d'Etudes Spatiales (CNES) and the Indian Space Research Organisation (ISRO). AltiKa's pulselimited Ka-band radar altimeter, which operates at a central frequency of $35.75 \mathrm{GHz}$, retrieves surface elevations up to 81.5 latitude. Armitage and Ridout (2015) used a "Gaussian plus exponential" retracker to retrieve lead elevations (after Giles et al., 2007) and a 50\% threshold retracker over floes. AltiKa freeboard data used in this study are derived using the same processing algorithm, and the reader is referred to the Supplement in Armitage and Ridout (2015) for further details.

\subsection{CryoSat-2}

CS-2 was launched by the European Space Agency in 2010, tasked with the specific role of monitoring the Earth's cryosphere. The satellite has an orbital inclination of $88^{\circ}$, giving it far better coverage over the poles than previous radar altimeters, and unlike AltiKa, CS-2 employs alongtrack SAR processing to achieve an along-track resolution of approximately $300 \mathrm{~m}$, improving the sampling of smaller floes and making it less susceptible to snagging from offnadir leads (Wingham et al., 2006). As with AltiKa, lead elevations are retrieved using the Gaussian plus exponential model fit and for floes a $70 \%$ threshold retracker was determined as offering the best average elevation from the CS-2 unique SAR waveforms (Wingham et al., 2006). The CS-2 freeboard data used in this study were processed by the Centre for Polar Observation and Modelling (CPOM) and readers are referred to Tilling et al. (2018) for further details on the method.

\subsection{Sources of AltiKa vs. CryoSat-2 freeboard bias}

We define AltiKa vs. CS-2 freeboard bias as the portion of the AltiKa minus CS-2 freeboard difference that does not originate from the difference in snow penetration of the two radars. In line with radar theory (Rapley et al., 1983) and in light of recent findings by Guerreiro et al. (2017), we expect such a bias to be the result of the difference in footprint 
Table 1. AltiKa and CS-2 (SAR mode) operation characteristics.

\begin{tabular}{|c|c|c|c|c|c|c|}
\hline & Period of operation & Operating frequency & Footprint size & Footprint area & $\begin{array}{l}\text { Sampling } \\
\text { interval }\end{array}$ & $\begin{array}{l}\text { Latitude } \\
\text { limit }\end{array}$ \\
\hline AltiKa & February 2013-present & $\begin{array}{l}35.75 \mathrm{GHz} \\
\text { (Ka-band radar) }\end{array}$ & $\begin{array}{l}1.4 \mathrm{~km} \text { diameter } \\
\text { (pulse-limited) }\end{array}$ & $1.5 \mathrm{~km}^{2}$ & $0.17 \mathrm{~km}$ & $81.5^{\circ}$ \\
\hline CryoSat-2 SAR & April 2010-present & $\begin{array}{l}13.57 \mathrm{GHz} \\
\text { (Ku-band radar) }\end{array}$ & $\begin{array}{l}0.3 \mathrm{~km}(1.7 \mathrm{~km}) \text { along (across) } \\
\text { track (Doppler cell) }\end{array}$ & $0.5 \mathrm{~km}^{2}$ & $0.3 \mathrm{~km}$ & $88^{\circ}$ \\
\hline
\end{tabular}

sizes between the two altimeters and the consequences of this during freeboard processing. The differences between AltiKa and CS-2 of interest to this study are summarised in Table 1.

In an initial stage of AltiKa and CS-2 freeboard processing, waveforms are classified as either lead or floe according to thresholds for pulse peakiness, defined as

$\mathrm{PP}=N \frac{p_{\max }}{\Sigma_{\mathrm{i}} p_{\mathrm{i}}}$,

where $N$ is the number of range bins above the "noise floor" (calculated as the mean power in range bins 10-20), $p_{\max }$ is the maximum waveform power (the "highest peak"), and $\Sigma_{\mathrm{i}} p_{\mathrm{i}}$ is the sum of the power in all range bins above the noise floor (Peacock and Laxon, 2004). It should also be noted that further waveform parameters are used to identify lead and floes: stack standard deviation (SSD) for CS-2 (Tilling et al., 2018) and backscatter coefficient $\sigma_{0}$ for AltiKa (Armitage and Ridout, 2015). Since PP is the criterion shared by both, it is the focus of our discussion here.

Waveforms originating from smooth, specular leads demonstrate a rapid rise in power followed by a sharp drop off, giving them a high PP. Returns from floes typically demonstrate a more gradual rise in power and slower dropoff, equivalent to a lower PP. PP can therefore be used to distinguish floe and lead returns and eliminate those not clearly identifiable as one or the other. For AltiKa (CS-2), waveforms with PP less than 5 (9) are designated as originating from ice floes. Waveforms with PP greater than 18 are classified as leads for both satellites (Armitage and Ridout, 2015; Tilling et al., 2018).

Waveforms that exhibit a mixture of scattering behaviour will have a PP in the "ambiguous" range $(5<\mathrm{PP}<18$ for AltiKa and $9<\mathrm{PP}<18$ for CS-2) and are discarded. Since AltiKa has a larger footprint, its waveforms are more likely to be ambiguous and therefore discarded than CS-2, which can resolve smaller floes within the same region. The result of this is a bias in AltiKa towards higher freeboards (only larger floes, which tend to be thicker, are captured), especially over seasonal lead-dense areas.

The impact of surface roughness on pulse-limited altimetry is well documented (e.g. Rapley et al., 1983; Raney, 1995; Chelton et al., 2001). Generally, a rougher surface leads to dilation of the footprint and a widening of the leading edge of the waveform return. For a homogeneously rough surface with a Gaussian surface elevation distribution, the $50 \%$ power threshold represents the mean surface elevation within the pulse-limited footprint. However, for a heterogeneously rough surface, such as that of multi-year sea ice, the waveform leading edge can take a complex shape where the halfpower point does not necessarily represent the average elevation within the footprint and using a $50 \%$ threshold retracker might lead to a biased surface height retrieval (Rapley et al., 1983; Raney, 1995; Chelton et al., 2001). Despite its along-track Doppler processing and effective sharpening of the waveform response, CS-2 may also be susceptible to an elevation bias due to surface roughness. This was demonstrated by Kurtz et al. (2014) who advocate the use of a physical model retracker in order to better resolve CS-2 surface elevation.

AltiKa is also more sensitive than CS-2 to off-nadir ranging to leads due to its larger footprint. This occurs when an off-nadir lead dominates the waveform response, resulting in an overestimate of the range to the lead, an underestimate of sea surface height, and a positive bias on the local floe freeboard (Armitage and Davidson, 2014). To minimise this effect, lead waveforms for AltiKa are discarded if their backscatter per unit area, $\sigma^{0}$, is less than $24 \mathrm{~dB}$, under the assumption that off-nadir leads return less power to the antenna compared with those at nadir (Armitage and Ridout, 2015). However, it is unlikely that this criterion eradicates the problem altogether and we expect that the freeboard bias due to snagging is larger in the AltiKa data compared to CS-2.

To overcome the CS-2 vs. AltiKa freeboard bias, Guerreiro et al. (2016) employed degraded SAR mode CS-2 data in their comparison, where the synthetic Doppler beams are not aligned in time and are summed incoherently to obtain a pseudo-pulse-limited echo. Since this offers a footprint and waveform more closely resembling that of AltiKa, it was assumed that observed elevation differences between AltiKa and degraded CS-2 were the result of differences in snow penetration only.

Rather than separating the contributions of freeboard difference in this way, we here introduce an approach that calibrates AltiKa freeboard to align it to the snow surface and CS-2 to the ice-snow interface (we assume in general that CS-2 penetrates further than AltiKa due to its longer wavelength, Ulaby et al., 1984). As such, penetration properties and sources of freeboard bias are corrected in one step without needing to consider the contribution of each. 
While the comparisons of Guerreiro et al. (2016) derived snow depths with those from OIB are encouraging, the assumption of zero penetration for AltiKa and full penetration for CS-2 introduces limitations and is counter to observational results (Giles and Hvidegaard, 2006; Willatt et al., 2011; Armitage and Ridout, 2015; Nandan et al., 2017) - and indeed their own model simulations - in support of a spatially and temporally variable penetration depth as a function of snow characteristics. Here we offer a methodology that both accounts for variable AltiKa and CS-2 snow penetration and is simple; freeboard data can be utilised as they are, without reprocessing. This is in contrast to the method of Guerreiro et al. (2016) which relies on the ability to process one of the satellite data sets to achieve comparable footprints and thus alleviate the biases due to the difference in sampling areas. It is fortunate that CS-2 pseudo-LRM (Low Resolution Mode) has a similar footprint to AltiKa ( $1.7 \mathrm{~km}$ diameter and $1.4 \mathrm{~km}$ diameter respectively), but how, for example, could the methodology be applied to CS-2 and ICESat-2 in order to retrieve contemporary snow depth estimates once AltiKa ceases functionality? Although herein we demonstrate our methodology applied to the AltiKa and CS-2 satellites, our intention is to outline an approach that can be applied more broadly. Given the recent launch of ICESat- 2 and the unique opportunity that its coincidence with CS-2 provides, we demonstrate the applicability of our method to the Envisat (same operating frequency as CS-2) and ICESat satellites.

\subsection{Operation IceBridge}

In order to evaluate the deviation of each satellite's retrieved elevation from its "expected" dominant scattering horizon (the snow surface for AltiKa and the snow-ice interface for CS-2), we use laser freeboard and snow depth from NASA's 2013-2016 OIB spring campaigns. It is important to note that a variety of research groups process OIB snow radar data in different ways, and the results vary significantly (for the 2013-2015 period, campaign-average snow depths differ by up to $7 \mathrm{~cm}$ over first-year ice and $12 \mathrm{~cm}$ over multi-year ice; Kwok et al., 2017). Evidently the lack of a singular, robust independent data set presents a limitation to our methodology since our aim is to calibrate to the "true" snow and ice freeboards. In an attempt to offer the best Dual-altimeter Snow Thickness product possible, we employ OIB snow depths processed from snow radar data by the NASA Jet Propulsion Laboratory (JPL), as these demonstrated best agreement with ERA-interim reanalysis data and the Warren climatology for the 2013-2015 period (Kwok et al., 2017). We return to a discussion on this limitation in Sect. 3.2.

Our methodology requires a comparison of CS-2 radar freeboard with OIB radar freeboard. To calculate this we use snow freeboard, retrieved using the OIB ATM (Airborne Topographic Mapper) laser altimeter, from which snow depth can be subtracted. Currently, ATM freeboard data are only available from the National Snow and Ice Data Center
(NSIDC), and for the 2014-2016 period these exist solely in Quick Look format: a first release, expedited version, which demonstrates reduced accuracy compared with the final release products (Kurtz, 2014). In the interest of consistency we also use the ATM laser freeboard Quick Look product for 2013.

Sea ice freeboard $f_{\mathrm{i}}$ is calculated by subtracting OIB JPL snow depth $h_{\mathrm{s}}$ from OIB Quick Look laser freeboard $f_{1}$. Ice freeboard is then converted to radar freeboard $f_{\mathrm{r}}$ by

$$
f_{\mathrm{r}}=f_{\mathrm{i}}-h_{\mathrm{s}}\left(\frac{c}{c_{\mathrm{s}}}-1\right) .
$$

The OIB radar freeboard represents the freeboard that would be retrieved by a satellite altimeter whose pulse penetrated through to the ice-snow interface (Armitage and Ridout, 2015). We choose a value of $c / c_{\mathrm{S}}$ of 1.28 after Kwok (2014). In the following discussion, AltiKa and CS-2 freeboard refers to the radar freeboard, that is the freeboard retrieved by the satellite before the correction for light propagation through the snowpack is applied.

\subsection{AltiKa calibration with Operation IceBridge}

For each day of the three spring campaigns 2013-2015, OIB laser freeboard data are averaged onto a $2^{\circ}$ longitude $\times 0.5^{\circ}$ latitude grid. Grid cells containing less than 50 individual points are discarded to remove speckle noise. Along-track AltiKa freeboard and PP data for the \pm 10 days surrounding the campaign day are then averaged onto the same grid, and grid cells with less than 50 points are similarly discarded. This grid and time window were chosen because they produced the maximum number of grid cells where a grid cell must contain at least 50 airborne and satellite points.

Satellite freeboard and PP grids are then interpolated at the average position of the OIB data within each valid OIB grid cell. Further, high resolution $(10 \mathrm{~km}$ gridded) ice type data from the EUMETSAT Ocean and Sea Ice Satellite Application Facility (OSI SAF, http://www.osi-saf.org, last access: 1 March 2018) are interpolated at the same point to determine whether multi-year or seasonal ice is being sampled. The value $\Delta f_{\mathrm{AK}}$, defined as the ATM laser freeboard minus the AltiKa freeboard and plotted against AltiKa PP, is shown in Fig. 1. Data from 2013, 2014, and 2015 and their corresponding linear regression fits are plotted in red, blue, and grey respectively to demonstrate year to year consistency. Multi-year and first-year ice are distinguished by star and square markers in order to illustrate the variation of PP, and thus roughness, with ice type.

The combined (all years) linear regression fit (CLRF) is shown by the black line and has slope of -0.16 and intercept of 0.76 . The shaded area shows the $68 \%$ prediction interval for the CLRF, corresponding to a standard error (SE) on $\Delta f_{\mathrm{AK}}$ of $9.4 \mathrm{~cm}$. The CLRF is greater than zero for most PPs, implying that the freeboard needs to be increased to align with the snow-air interface, though more so $(\sim 0.2 \mathrm{~m})$ 


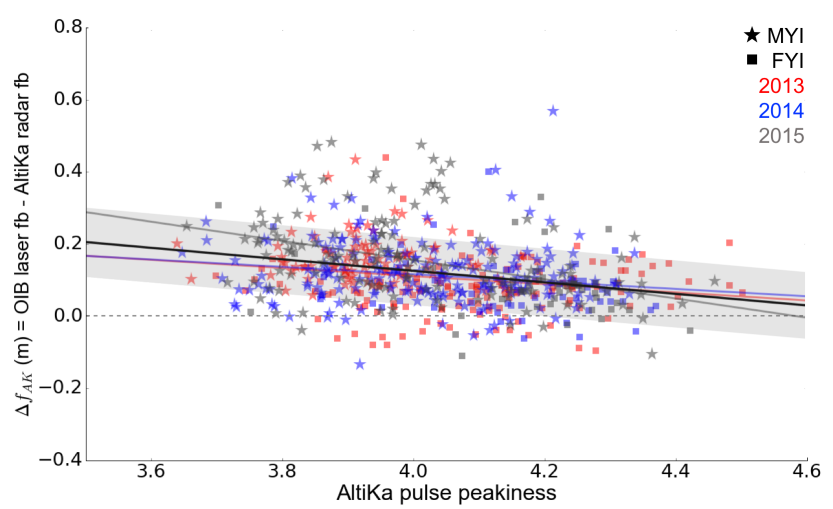

Figure 1. The value $\Delta f_{\mathrm{AK}}$, defined as the OIB laser freeboard minus the AltiKa radar freeboard, plotted against AltiKa pulse peakiness, for the OIB spring campaigns of 2013 (red), 2014 (blue), and 2015 (grey). Multi-year and first-year ice are plotted with stars and squares respectively, and the horizontal grey dashed line marks zero. The combined (all years) linear regression fit (CLRF), shown by the black line, has a slope of -0.16 and an intercept of 0.76 . The shaded area around the CLRF shows the $68 \%$ prediction interval, corresponding to a standard error $(\mathrm{SE})$ on $\Delta f_{\mathrm{AK}}$ of $9.4 \mathrm{~cm}$. Please note that $\mathrm{fb}$ is freeboard.

for low peakiness values (rougher ice) than for high peakiness values (smoother ice), where the correction approaches zero. This suggests that freeboard over rough ice is biased low, which could be attributed to difficulty in identifying the average footprint surface elevation as outlined in Sect. 2.3. It could also suggest that AltiKa exhibits greater snow penetration over rough ice than seasonal ice, in support of the assumption that (i) rough, multi-year ice has a thicker snow cover and (ii) seasonal ice is likely subject to brine wicking, which prevents radar propagation through the snow (Nandan et al., 2017). Ultimately we cannot separate the influence of individual sources of bias and physical penetration, and therefore, these observations are purely speculative.

\subsection{CS-2 calibration with Operation IceBridge}

The procedure for calibrating CS-2 with OIB is identical to that outlined above for AltiKa, but here $\Delta f_{\mathrm{CS}}$ is defined as the OIB radar freeboard (see Sect. 2.4) minus the CS-2 radar freeboard. For consistency and comparability with AltiKa, we remove CS- 2 data above $81.5^{\circ} \mathrm{N}$ from our analysis. The value $\Delta f_{\mathrm{CS}}$ is plotted against CS-2 PP and shown in Fig. 2 . The CLRF, shown by the black line, has a slope of 0.06 and a negative intercept of -0.46 . As before, the shaded area around the CLRF shows the $68 \%$ prediction interval, and corresponds to a $\pm 8.4 \mathrm{~cm}$ uncertainty (1 standard error) on $\Delta f_{\mathrm{CS}}$.

For the entire CS-2 PP range, the CLRF is negative. It is most negative at lower PP, indicating that the CS-2 freeboard lies higher above the snow-ice interface over rough ice. This is in agreement with rougher ice exhibiting thicker

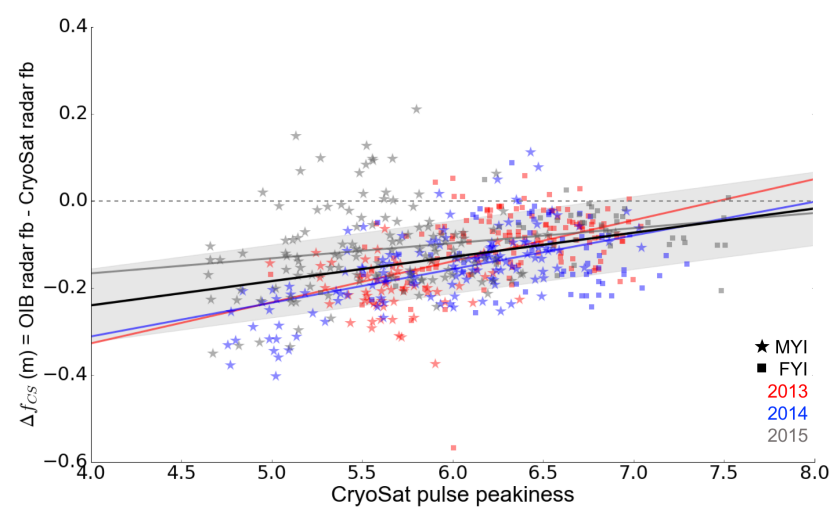

Figure 2. The value $\Delta f_{\mathrm{CS}}$, defined as the OIB theoretical radar freeboard minus the CS-2 radar freeboard, plotted against CS-2 pulse peakiness, for the OIB spring campaigns of 2013 (red), 2014 (blue), and 2015 (grey). Multi-year and first-year ice are plotted with stars and squares respectively, and the horizontal grey dashed line marks zero. The combined (all years) linear regression fit (CLRF), shown by the black line, has a slope of 0.06 and an intercept of -0.46 . The shaded area around the CLRF shows the $68 \%$ prediction interval, corresponding to a standard error (SE) on $\Delta f_{\mathrm{CS}}$ of $8.4 \mathrm{~cm}$. Please note that $\mathrm{fb}$ is freeboard.

snow cover and the radar pulse therefore being limited from getting as close to the snow-ice interface, where the snow is thinner. This deviation could also be the result of a failure of the empirical retracker to retrieve accurate surface elevation over rough ice, as demonstrated by Kurtz et al. (2014). As before, since we cannot separate the influence of individual sources of bias and physical penetration, these suggestions are speculative.

\section{Results and discussion}

\subsection{Case study November 2015-April 2016}

To derive snow depth, along-track freeboard measurements for AltiKa and CS-2 are calibrated as a function of PP according to the combined linear regression fits derived in the previous section and then averaged onto a $1.5^{\circ}$ longitude by $0.5^{\circ}$ latitude monthly grids. A finer grid resolution than for the calibration analysis is afforded given the coverage of 1 month's worth of data as compared to the 21 days ( \pm 10 days window) averaged previously. The calibrated CS-2 freeboard is subtracted from the calibrated AltiKa freeboard and multiplied by a factor of $c_{\mathrm{s}} / c$ $=0.781$ to convert to snow depth. Figure 3 summarises the retrieved monthly dual-altimeter snow thicknesses from November 2015 to April 2016. The delineation of multi-year and first-year ice is shown by the dashed black lines, adapted from OSI SAF Quicklook daily sea ice type maps for the 15th day of each month, available at http://osisaf.met.no/p/ osisaf_hlprod_qlook.php?prod=Ice-Type \&area=NH (last access: 1 March 2018). 
(a) November

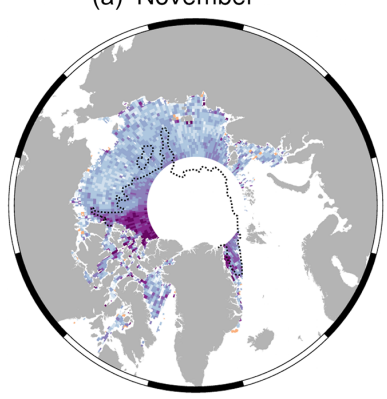

(d) February

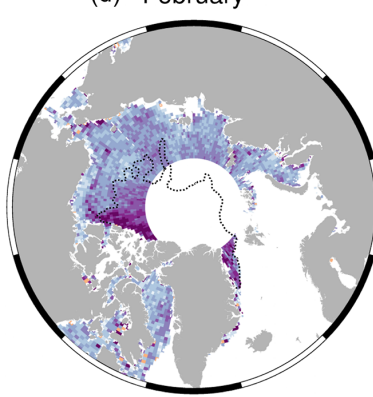

(b) December

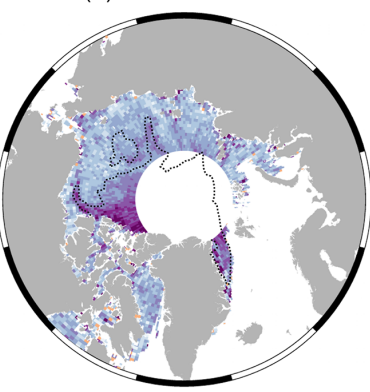

(e) March
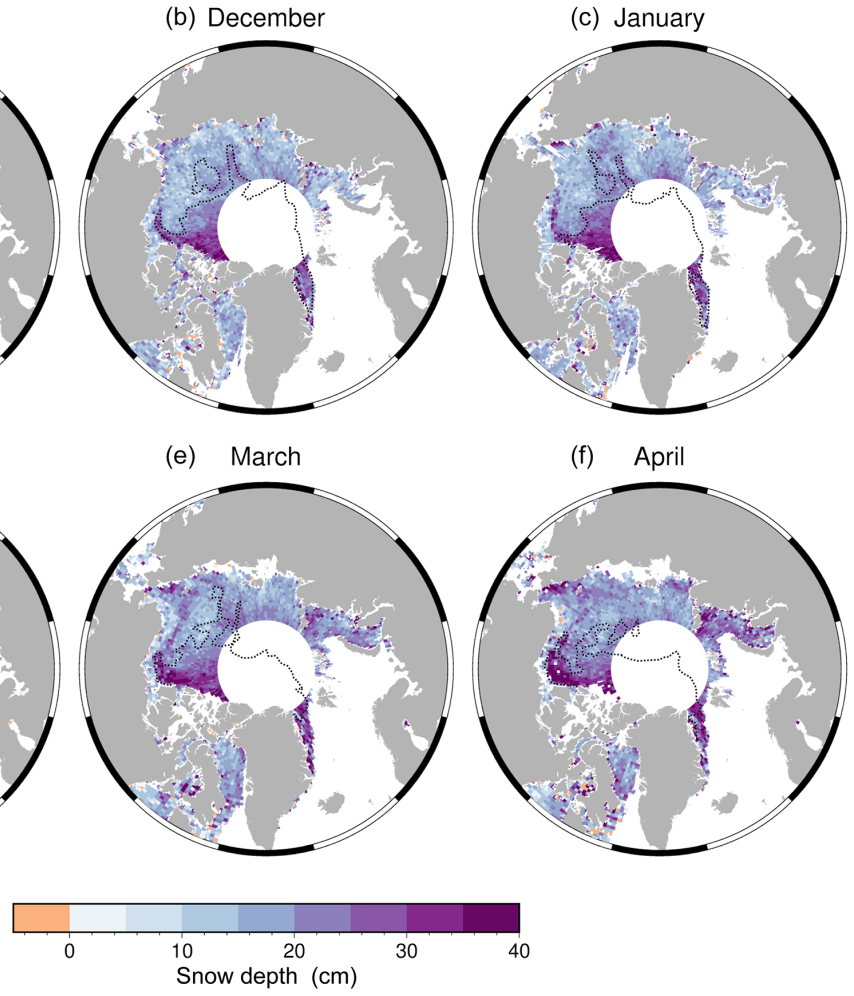

Figure 3. Monthly snow depths for the growth season November 2015 (a) to April 2016 (f), derived from the AltiKa minus CS-2 calibrated freeboard. The multi-year ice boundary for each month is shown by the dashed black line, adapted from the OSI SAF Quicklook sea ice type map for the 15th day of the month, available at http://osisaf.met.no/p/osisaf_hlprod_qlook.php?prod=Ice-Type\&area=NH (last access: 1 March 2018).

Spatial distribution of snow depth follows the expected pattern of thin snow cover over seasonal ice (up to $25 \mathrm{~cm})$ and thicker snow over multi-year ice $(30-40 \mathrm{~cm})$ (Warren et al., 1999), which in recent years is limited to regions north of the Canadian Archipelago (CAA) and Greenland and the Fram Strait. However, seasonal deposition of snow occurs between November and April, corresponding with the locations of predominant cyclone tracks in winter (e.g. the Aleutian Low on the Pacific side and the North Atlantic storm tracks). In particular, snow predominantly accumulates within the Chukchi Sea, and within the Kara, Barents, and eastern Greenland seas. As well as precipitation events, ice drift governs snow distribution through the advection of snow-loaded sea ice parcels around the ocean. Therefore, in order to understand the seasonal evolution of the snow cover, we compare snow depth maps with monthly sea ice motion vectors from the National Snow and Ice Data Center (NSIDC, available at https://daacdata.apps.nsidc.org, last access: 23 February 2018), shown in Fig. 4. We expect snow accumulation west of Banks Island in the CAA is the result of westward transport of multi-year ice by the Beaufort Gyre. Snow depths in the Kara Sea appear high given the advection of ice out of this region throughout the season; however, we cannot rule out anomalous precipitation events.
Typically 20-40 extreme cyclones occur each winter within the North Atlantic, but in recent years there has been a trend towards increased frequency of cyclones, particularly near Svalbard (Rinke et al., 2017). These cyclones, while they transport heat and moisture into the Arctic and may impact the sea ice edge location (Boisvert et al., 2016; Ricker et al., 2017), can also be associated with increased precipitation.

To understand where greatest accumulation of snow occurs over the season, we also plot the difference between November 2015 and April 2016 snow depth in Fig. 5. Snow accumulation is highest in the western Beaufort Sea, in particular adjacent to the coast of Canada. We attribute this to the advection of snow-loaded multi-year ice by the Beaufort Gyre, supported by the visible shift of the multi-year ice boundary through the season (Fig. 3). Accumulation also occurs in the Fram Strait, which we expect to be the result of southward advection of multi-year ice from the central Arctic Ocean in December and April, as well as snow deposition from the North Atlantic Storm tracks. High accumulation in the southern Chukchi Sea could also be explained by strong advective currents pushing snow-loaded ice into this area, particularly from November to January, as well as snow precipitation from the Aleutian Low. Negative snow depth changes are generally small, and are predominantly visible 


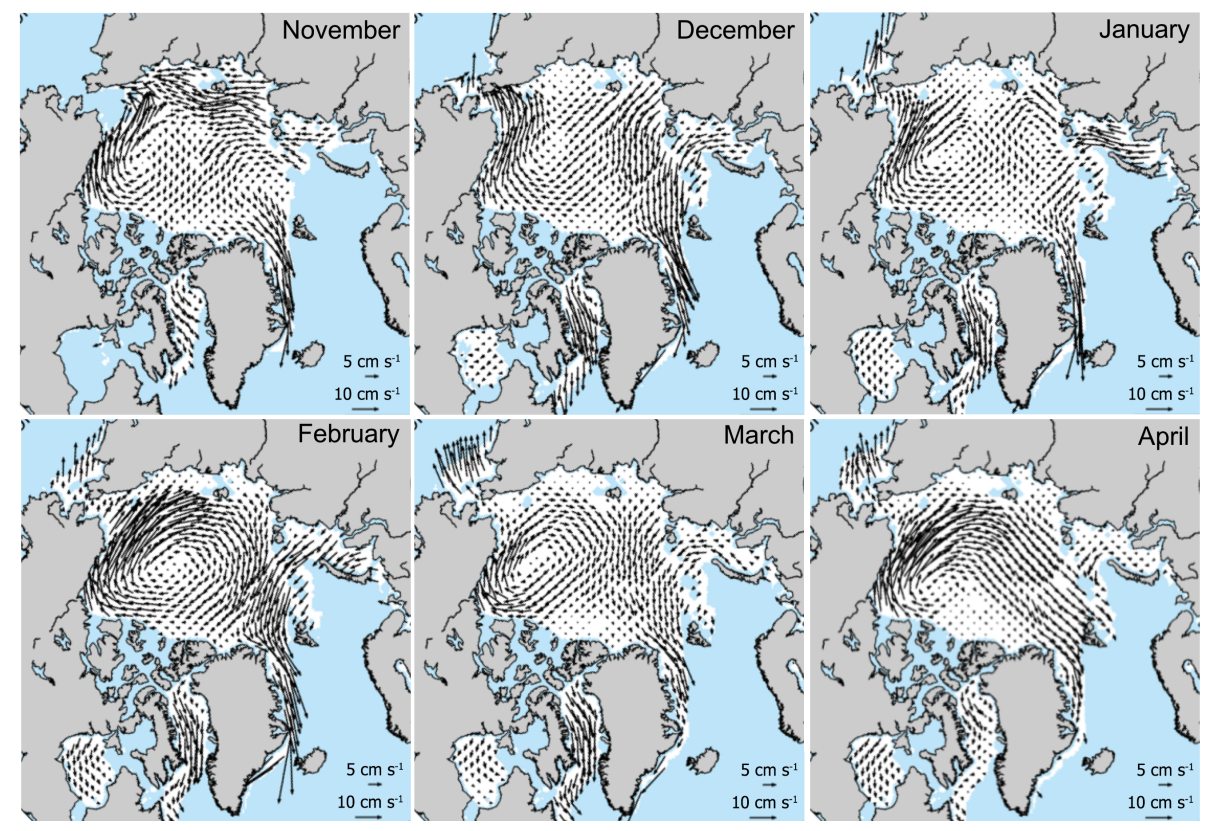

Figure 4. NSIDC November 2015 to April 2016 monthly mean sea ice drift vectors. Adapted from images retrieved from https://daacdata. apps.nsidc.org/pub/DATASETS/nsidc0116_icemotion_vectors_v3/browse/north/ (last access: 23 February 2018).

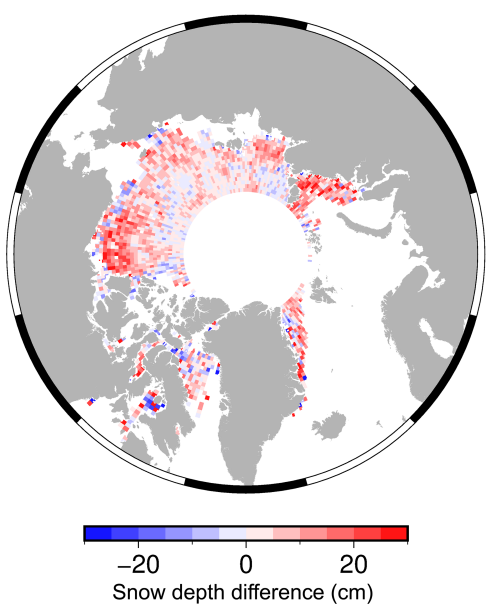

Figure 5. April 2016 minus November 2015 DuST.

in the centre of the Beaufort and Laptev seas. In accordance with Fig. 4 we expect these negative accumulations to be the result of advection transporting snow-loaded ice parcels out of these regions and perhaps new ice formation.

One limitation of the AltiKa CS-2 DuST product is the data gap associated with AltiKa's upper latitudinal limit of $81.5^{\circ} \mathrm{N}$. This region contains a large proportion of the Arctic's thick multi-year ice, and thus, observations of snow depth could provide valuable insight as the ice pack transitions from multi-year to first-year ice. Furthermore, for a snow depth product to be useful for integration into sea ice thickness retrievals as discussed in the introduction, one that extends to the CS-2 latitude range is desirable. Application of the DuST methodology to the CS-2 and ICESat-2 satellites would generate a snow depth product up to $88^{\circ}$. Alternatively, dual-frequency operation from the same satellite platform would open the potential for snow depth retrievals along the satellite track.

A secondary limitation of the methodology is the extent of the OIB campaigns; since they only operate in the western Arctic Ocean, north of the CAA, and in the Lincoln and Beaufort seas, no observations from the eastern Arctic go into our calibrations. Thus, the calibration functions derived are unconstrained outside of this area and we have less confidence in the snow depths in the eastern Arctic. Further, the calibration relationships are only strictly valid in spring, when OIB operates, so caution is warranted in using these products for seasonal variability of snow depth analysis.

\subsection{Uncertainty calculation}

The uncertainty calculation performed in this section assumes that the OIB products used in the analysis contain no systematic bias. We expect random noise to be minimised by grid averaging, but any systematic error would offset the calibration linear regression fits and alter snow depth retrievals. As discussed in Sect. 2.4, the recent study by Kwok et al. (2017) highlights the differences that exist between OIB snow radar data processed using various existing algorithms. It is not within the scope of this study to assess the sensitivity of our DuST product to the different OIB snow radar input data, but it remains the subject of future work. One purpose of the Kwok et al. (2017) inter-comparison was to identify 
Table 2. Covariances between terms for snow depth uncertainty calculation.

\begin{tabular}{lrrrrrr}
\hline Covariance term & $\sigma_{f_{\mathrm{AK}} \Delta f_{\mathrm{AK}}}$ & $\sigma_{f_{\mathrm{AK}} f_{\mathrm{CS}}}$ & $\sigma_{f_{\mathrm{AK}} \Delta f_{\mathrm{CS}}}$ & $\sigma_{\Delta f_{\mathrm{AK}} f_{\mathrm{CS}}}$ & $\sigma_{\Delta f_{\mathrm{AK}} \Delta f_{\mathrm{CS}}}$ & $\sigma_{f_{\mathrm{CS}} \Delta f_{\mathrm{CS}}}$ \\
\hline Value & 0.0013 & 0.0063 & -0.0027 & 0.0010 & -0.0010 & -0.0027 \\
\hline
\end{tabular}

the strengths and weaknesses of each processing technique in order to inform the design of an optimised algorithm and generate an improved snow radar product. We acknowledge that our methodology would benefit from such an effort and suggest that for future applications of this methodology - in particular to CS-2 and ICESat-2 - the next-generation of OIB snow depths should be investigated.

The equation for calculating snow depth, $h_{\mathrm{s}}$, by our methodology is

$h_{\mathrm{s}}=0.781\left(\left(f_{\mathrm{AK}}+\Delta f_{\mathrm{AK}}\right)-\left(f_{\mathrm{CS}}+\Delta f_{\mathrm{CS}}\right)\right)$,

where $f_{\mathrm{AK}}$ and $f_{\mathrm{CS}}$ are the AltiKa and CS-2 freeboards, and $\Delta f_{\mathrm{AK}}$ and $\Delta f_{\mathrm{CS}}$ are the AltiKa and CS-2 freeboard corrections (see Sect. 2.5 and 2.6). From propagation of errors on Eq. (2), the uncertainty on snow depth, $\sigma_{h_{\mathrm{s}}}$, is given by

$$
\begin{aligned}
\sigma_{h_{\mathrm{s}}}= & 0.781\left(\sigma_{f_{\mathrm{AK}}}^{2}+\sigma_{\Delta f_{\mathrm{AK}}}^{2}+\sigma_{f_{\mathrm{CS}}}^{2}+\sigma_{\Delta f_{\mathrm{CS}}}^{2}\right. \\
& +2 \sigma_{f_{\mathrm{AK}} \Delta f_{\mathrm{AK}}}-2 \sigma_{f_{\mathrm{AK}} f_{\mathrm{CS}}}-2 \sigma_{f_{\mathrm{AK}} \Delta f_{\mathrm{CS}}} \\
& \left.-2 \sigma_{\Delta f_{\mathrm{AK}} f_{\mathrm{CS}}}-2 \sigma_{\Delta f_{\mathrm{AK}} \Delta f_{\mathrm{CS}}}+2 \sigma_{f_{\mathrm{CS}} \Delta f_{\mathrm{CS}}}\right)^{\frac{1}{2}}
\end{aligned}
$$

where the first four terms are the errors on the four variables in Eq. (2), and the last six terms are the covariances between them.

We obtain values of $\sigma_{f_{\mathrm{AK}}}=9.4 \mathrm{~cm}$ and $\sigma_{f_{\mathrm{CS}}}=8.4 \mathrm{~cm}$ from the $68 \%$ prediction intervals on the calibration fits, represented by the shaded areas in Figs. 1 and 2 respectively.

Since our snow product is monthly gridded we are interested in monthly gridded snow depth uncertainty. Therefore $\sigma_{f_{\mathrm{AK}}}$ and $\sigma_{f_{\mathrm{CS}}}$ are the errors on the monthly gridded satellite freeboards to which the calibration corrections are being applied. According to Tilling et al. (2018), the error on the monthly gridded CS-2 freeboard is dominated by the uncertainty on the interpolated sea level anomaly (SLA), calculated from the SLAs of waveforms identified as leads (see Sect. 2.3). Lead SLAs within a $200 \mathrm{~km}$ along-track window centred on each floe measurement are fit with a linear regression to estimate the SLA beneath the floe and thus calculate the freeboard. As such, along-track floe measurements are not decorrelated at length scales less than $200 \mathrm{~km}$, and the interpolated SLA uncertainty is not reduced from grid-cell averaging of data from the same satellite pass. Since the interpolation is performed along-track, separate satellite passes over each grid cell over the month are decorrelated, and thus the error is minimised by $1 / \sqrt{N}$, where $N$ is the number of passes over a grid cell in 1 month. To calculate this error we reprocessed 1 month (January 2016) of CS-2 and AltiKa data, recording for each floe freeboard retrieval the $68 \%$ prediction interval on the linear regression fit across the $200 \mathrm{~km}$ window. These errors, averaged on our $1.5^{\circ}$ longitude by $0.5^{\circ}$ latitude grid are shown in Fig. 6a. Since this error decorrelates from one satellite pass to the next, we divide by the number of satellite passes in a month (Fig. 6b) to retrieve the final interpolated SLA uncertainty, shown in Fig. 6c. Since this error dominates the freeboard retrieval (Tilling et al., 2018), this approximates to the monthly uncertainty on AltiKa and CS-2 freeboards, $\sigma_{f_{\mathrm{AK}}}$ and $\sigma_{f_{\mathrm{CS}}}$.

The last six terms of Eq. (3) are the covariances of the four variables. We calculate these by gridding all AltiKa and CS-2 data from March 2013 to January 2018 and finding the correlation-covariance matrix. The value for each term is summarised in Table 2.

All terms are substituted into Eq. (3) to find the uncertainty $\sigma_{h_{\mathrm{s}}}$ on monthly gridded snow depth, shown for January 2016 in Fig. 7. The uncertainty is higher at lower latitudes where there are less satellite passes per grid cell, and over the thick multi-year ice to the north of the CAA where fewer leads available for the linear regression increase the uncertainty on the interpolated SLA, particularly for CS-2 (see Fig. 6a). As a conservative estimate we assign our monthly gridded snow depth product an average uncertainty of $8 \mathrm{~cm}$ for all months.

The main contribution to snow depth uncertainty is the prediction intervals from the calibration functions (see Sect. 2.5 and 2.6). This uncertainty could be reduced with the addition of more data points, i.e. more seasons of coincident satellite and OIB measurements. At time of publication OIB data for springs 2017 and 2018 have not been made publicly available.

\subsection{Comparison with Operation IceBridge}

We compare snow depth retrieved by our methodology with OIB snow depths from spring 2016 following the same procedure outlined in Sect. 2.5 and 2.6. For each day of the 2016 campaign, OIB snow depths are averaged onto the $2^{\circ}$ longitude $\times 0.5^{\circ}$ latitude grid, and grid cells containing less than 50 individual points are discarded to remove speckle noise, as before. Calibrated AltiKa and CS-2 freeboards for the \pm 10 days surrounding the campaign day are averaged onto the same grid and grid cells with less than 50 AltiKa or CS-2 points are discarded. The gridded, calibrated CS2 freeboard is subtracted from the gridded calibrated AltiKa freeboard and multiplied by factor $c_{\mathrm{s}} / c=0.781$, as done previously. The resulting snow depth grid is then interpolated at the average position of the OIB data within each valid OIB 

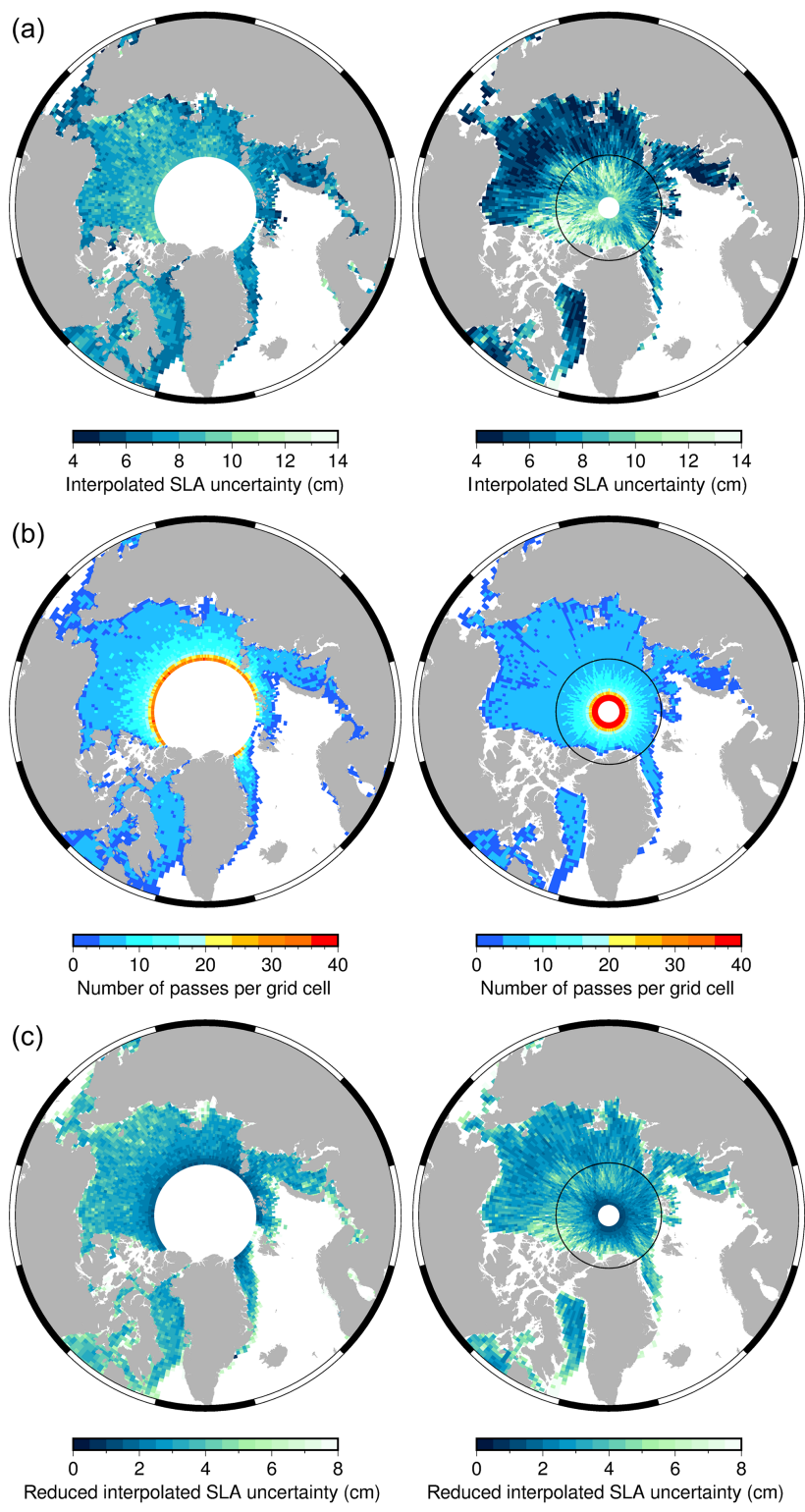

Figure 6. Satellite freeboard error calculation for January 2016 for AltiKa (left) and CS-2 (right). (a) Monthly gridded sea level anomaly (SLA) error. (b) Number of tracks per $\left(1.5^{\circ}\right.$ long $\times 0.5^{\circ}$ lat) grid cell per month. (c) SLA error divided by the square root of the number of tracks, i.e. (a) $/ \sqrt{(\mathrm{b})}$ gives the reduced monthly error on freeboard. The black circle on the CS-2 maps shows the upper latitude limit of DuST $\left(81.5^{\circ} \mathrm{N}\right)$.

grid cell. The DuST retrieved for each point is plotted against OIB snow depth.

In order to compare with more than one OIB campaign, we repeated the original calibration analyses outlined in Sect. 2.6 and 2.5, successively omitting each of the 2013-2015 OIB seasons and using the other 3 years' data to derive calibration functions and generate snow depths for the omitted year. DuST snow depths were then compared against OIB snow

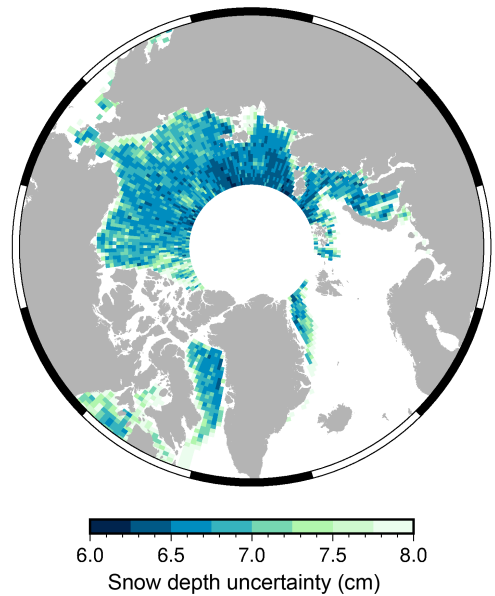

Figure 7. January 2016 snow depth uncertainty.

Table 3. Results of OIB and DuST comparison for the years 20132016.

\begin{tabular}{lllll}
\hline & 2013 & 2014 & 2015 & 2016 \\
\hline $\begin{array}{l}\text { Root-mean-square } \\
\text { deviation (RMSD) }\end{array}$ & $7.7 \mathrm{~cm}$ & $5.3 \mathrm{~cm}$ & $5.9 \mathrm{~cm}$ & $6.7 \mathrm{~cm}$ \\
$\begin{array}{l}\text { Difference in means } \\
\text { Pearson Coefficient } R\end{array}$ & $\begin{array}{l}2.12 \mathrm{~cm} \\
0.58\end{array}$ & $0.92 \mathrm{~cm}$ & $1.29 \mathrm{~cm}$ & $0.03 \mathrm{~cm}$ \\
\hline
\end{tabular}

depths by the method outlined in the previous paragraph. Results for all 4 years are shown in Fig. 8 and summarised in Table 3.

Since OIB data were used to calibrate the satellite freeboards, this cannot be considered a validation exercise. However, if OIB is considered as providing true snow depth estimates (see discussion in Sect. 2.4 and 3.2), then the results suggest the ability to use the derived calibration relationships to predict snow depth when OIB does not operate, e.g. in future. The poor agreement between DuST and OIB for 2013 as compared to subsequent years could relate to the persistence and treatment of radar side lobes in the 2013 data (Kwok et al., 2017). Our analysis would benefit from the inclusion of additional OIB campaign data in the calibration and comparison. At present, OIB data for 2017 and 2018 are not available.

\subsection{Application of DuST to ICESat-Envisat}

The methodology outlined above demonstrates the ability to calibrate satellite freeboards with an independent data set in order to derive snow depth. It can be applied to any two coincident freeboard data sets and could be applicable to ICESat-2 which launched in September this year. In view of this possibility, we applied the methodology to the ICESat and Envisat satellites, whose periods of operation overlapped between 2003 and 2009. 


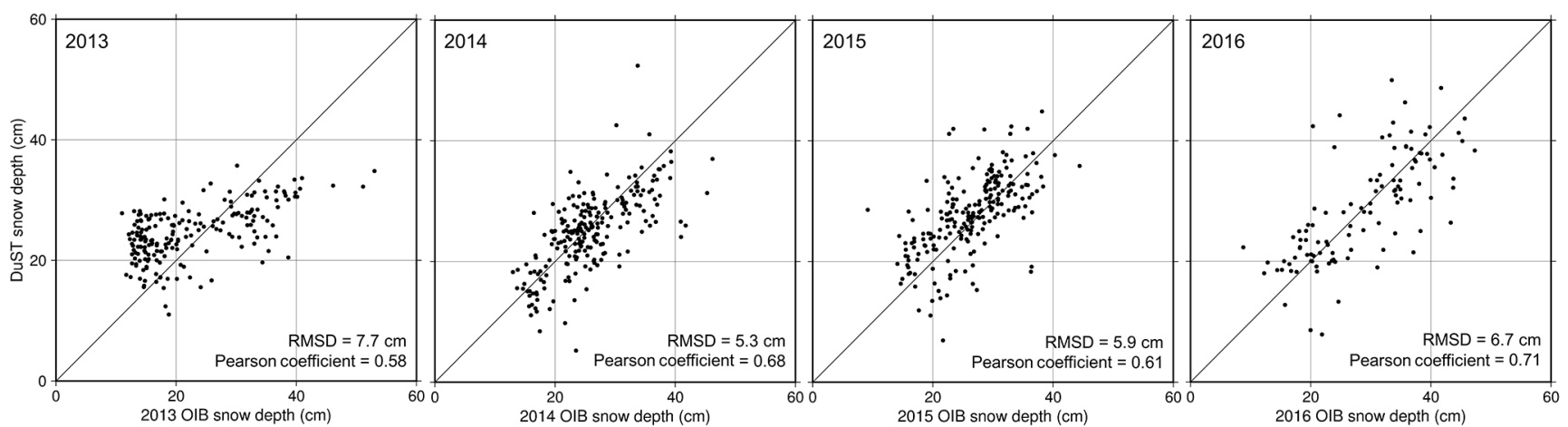

Figure 8. Comparison of DuST and OIB snow depths for the 2013, 2014, 2015, and 2016 spring campaigns. Statistical results for all years are summarised in Table 3.
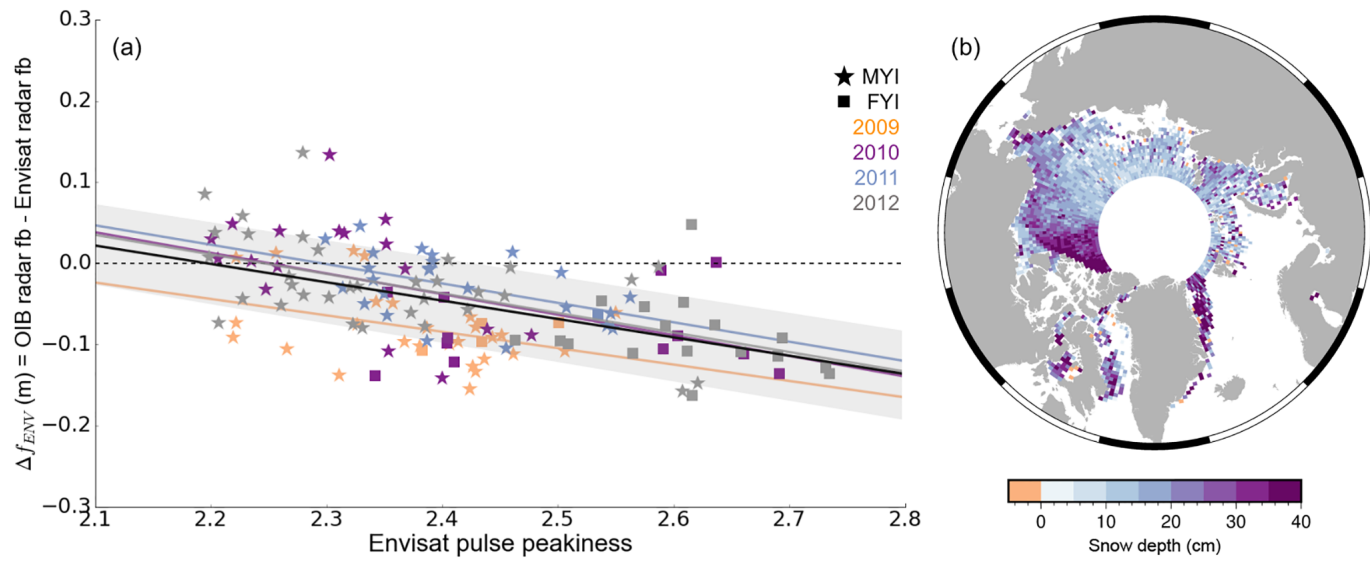

Figure 9. (a) Envisat calibration relationship, derived from comparison of coincident OIB and Envisat data. Data and corresponding linear regression fits for 2009, 2010, 2011, and 2012 are shown in orange, purple, blue, and grey respectively. Star and square symbols represent multi-year and seasonal ice respectively, and the horizontal grey dashed line shows zero. (b) Snow depth for ICESat's 3E laser period (22 February-27 March 2006), retrieved by subtracting the calibrated Envisat freeboard from the ICESat freeboard and multiplying by a factor of 0.781 . Please note that fb is freeboard.

The Radar Altimeter 2 (RA2) instrument operated on the Envisat satellite from 2002 until 2012. It was a pulse-limited Ku-band radar altimeter which like that aboard CS-2, operated at a central frequency of $13.575 \mathrm{GHz}$. NASA's ICESat mission featured a Geoscience Laser Altimeter System (GLAS) in order to accurately measure changes in the elevation of the Antarctic and Greenland ice sheets. This laser was also used to estimate ice thickness from laser freeboard retrieval (e.g. Kwok et al., 2007). Between 2003 and 2009, ICESat completed 17 observational campaigns; once every spring (February-March) and autumn (October-November) as well as three in the summers of 2004, 2005, and 2006.

ICESat had a $70 \mathrm{~m}$ diameter footprint, so we assume that biases due to footprint size or retracking method are negligible, and that it offers accurate estimates of the snow freeboard. We use available ICESat freeboard data (version 1) from NSIDC (Yi and Zwally, 2009, updated 2014), in our analysis. Envisat freeboard data were processed by CPOM, and the reader is referred to Ridout and Ivanova (2013) for further details on the algorithm.

Following the procedure outlined in Sect. 2.5, Envisat freeboard is calibrated to the snow-ice interface. Envisat has a larger footprint than AltiKa, nominally $2-10 \mathrm{~km}$ in diameter (Connor et al., 2009). As such, the waveform returns are more often classified as ambiguous (showing a complex mixture of scattering behaviour) and discarded, as discussed with reference to AltiKa in Sect. 2.3. As a result, Envisat data are sparsely populated and in order to have sufficient coverage for comparison with OIB data as well as 50 or more points per grid cell (to reduce speckle noise), it was necessary to increase both the grid resolution and time window as compared with the calibration procedure performed for AltiKa and CS-2.

Satellite data for the \pm 15 days surrounding each 2009 2012 OIB campaign day were averaged onto a $3^{\circ}$ longitude $\times 0.75^{\circ}$ latitude grid. The value $\Delta f_{\mathrm{ENV}}$, defined as the OIB radar freeboard minus the Envisat freeboard and plotted 
against Envisat PP, is shown in Fig. 9a. The combined (all years) linear regression fit is shown by the black line and has slope of -0.23 and intercept 0.50 . The shaded area shows the $68 \%$ prediction interval for the CLRF, corresponding to a $\pm 5 \mathrm{~cm}$ standard error on $\Delta f_{\mathrm{ENV}}$.

Dual-altimeter snow thickness, retrieved by subtracting the calibrated Envisat freeboard from the ICESat freeboard, is shown in Fig. 9b for the ICESat laser period 3E (22 February-27 March 2006). Snow depth spatial distribution follows the expected pattern of thicker snow $(30-40 \mathrm{~cm})$ over multi-year ice to the north of the Canadian Archipelago and in the Fram Strait, and thinner snow cover $(<20 \mathrm{~cm})$ over seasonal ice. Overall higher magnitudes as compared with March 2016 (Fig. 3) could be the result of a decline in multi-year ice fraction and precipitation over the past decade. Though validation is required, the result demonstrates the viability of combining laser and calibrated radar freeboards to retrieve snow depth.

\section{Conclusions}

Using independent snow and ice freeboard data from OIB, we derived calibration relationships to align AltiKa to the snow surface and CS-2 to the ice-snow interface as a function of their pulse peakiness. Calibrated CS-2 and AltiKa freeboard data were then combined to generate spatially extensive snow depth estimates across the Arctic Ocean between 2013 and 2016.

The Dual-altimeter Snow Thickness (DuST) product was evaluated against OIB snow depth by successively omitting each year of OIB data from the calibration procedure, returning root-mean-square deviations of 7.7, 5.3, 5.9 , and $6.7 \mathrm{~cm}$ for the years 2013, 2014, 2015, and 2016 respectively. While the OIB snow depth data cannot be considered statistically independent validation of the DuST product, this evaluation does demonstrate the ability to upscale OIB snow depths to the wider Arctic, i.e. predict OIB snow depths for an unsampled region and year. However, the DuST snow depth estimates remain unconstrained and unevaluated outside of the western Arctic and the spring season, due to a lack of coincident data. We used OIB snow radar data processed by NASA JPL in our analysis since this demonstrated best agreement with ERA-interim and the Warren climatology for the years 2013-2015; however, our methodology would benefit from the development of an optimal snow radar processing algorithm and snow depth product. Investigating the sensitivity of our product to the discrepancies between existing OIB snow radar data versions remains the subject of future work.

The upcoming Multidisciplinary drifting Observatory for the Study of Arctic Climate (MOSAiC) campaign in autumn 2019 will provide a unique opportunity for validating DuST in regions not sampled by OIB (e.g. the eastern Arctic) throughout a full annual cycle. A dedicated dual-radar study is planned during the MOSAiC experiment, using in situ and on-aircraft Ku-Ka-band radar to quantify radar backscatter at each frequency together with snow depth and ice thickness measurements. This, in conjunction with AltiKa and CS-2 observations, will provide valuable insight into the validity of our calibration functions and retrieved DuST snow depths.

Our methodology can also be applied to retrieve snow depth from coincident satellite radar and laser altimetry, which will have particular relevance when data from ICESat2, launched in September 2018, become available. Here, we tested the applicability of the method to the ICESat and Envisat satellites, offering promising potential for the future retrieval of snow depth on Arctic sea ice from CS-2 and ICESat-2, with better coverage over the pole.

Data availability. Satellite freeboard data: CryoSat-2 and Envisat along-track freeboard data used in this study were processed by the Centre for Polar Observation and Modelling (CPOM) and are available on request. AltiKa altimeter products were produced and distributed by Aviso+ (https://www.aviso.altimetry.fr/, last access: 21 October 2018) as part of the Ssalto ground processing segment. AltiKa waveform data, available via the site ftp://avisoftp.cnes.fr/AVISO/pub/saral/sgdr_t/ (last access: 28 February 2018) were processed into freeboard using the processor outlined in Armitage and Ridout (2015). ICESat freeboard is available from https://nsidc.org/data/nsidc-0393 (last access: $1 \mathrm{Au}-$ gust 2017). Auxiliary data: Operation IceBridge ATM Quick Look data are hosted at the National Snow and Ice Data Center (NSIDC, https://nsidc.org/data/docs/daac/icebridge/evaluation_products/ sea-ice-freeboard-snowdepth-thickness-quicklook-index.html, last access: 14 October 2016). Sea ice type is a product of the EUMETSAT Ocean and Sea Ice Satellite Application Facility (OSI SAF, http://www.osi-saf.org, last access: 1 March 2018). Daily gridded ice type fields can be accessed via the FTP site: ftp://osisaf.met.no/archive/ice/type (last access: 1 March 2018) and daily Quicklook Ice Type maps are available at http://osisaf. met.no/p/osisaf_hlprod_qlook.php?prod=Ice-Type\&area=NH (last access: 1 March 2018). Sea ice motion vectors are distributed by NSIDC and can be found at: https://daacdata.apps.nsidc.org/pub/ DATASETS/nsidc0116_icemotion_vectors_v3/browse/north/ (last access: 23 February 2018). Output data: The AltiKa-CryoSat-2 and ICESat-Envisat Dual-altimeter Snow Depth (DuST) products are available at http://www.cpom.ucl.ac.uk/DuST (last access: 11 November 2018).

Author contributions. IRL carried out the presented analysis and wrote the manuscript, with support from MCT, JCS, and TWKA. TWKA and ALR wrote the AltiKa and CryoSat-2 processors for the derivation of satellite freeboard and offered technical support in their implementation and adaptation by IRL.

Competing interests. The authors declare that they have no conflict of interest. 
Acknowledgements. This work was funded primarily by the London National Environmental Research Council Doctoral Training Partnership grant (NE/L002485/1) and in part by the Arctic+ European Space Agency snow project ESA/AO/1-8377/15/I-NB NB - "STSE - Arctic+". The authors wish to thank Ron Kwok, NASA Jet Propulsion Laboratory, for the use of his OIB snow radar data and Richard Chandler, University College London, for help in preparing this manuscript. Thomas Armitage was supported at the Jet Propulsion Laboratory, California Institute of Technology, under a contract with the National Aeronautics and Space Administration. CryoSat-2 and Envisat data were provided by the European Space Agency and processed by the Centre for Polar Observation and Modelling. AltiKa data were provided by AVISO. ICESat freeboard, Operation IceBridge data, and sea ice motion vectors were provided by the National Snow and Ice Data Center. Sea ice type masks were provided by the Ocean and Sea Ice Satellite Application Facilities.

Edited by: Dirk Notz

Reviewed by: two anonymous referees

\section{References}

Armitage, T. W. K. and Davidson, M. W. J.: Using the Interferometric Capabilities of the ESA CryoSat-2 Mission to Improve the Accuracy of Sea Ice Freeboard Retrievals, IEEE T. Geosci. Remote, 52, 529-536, https://doi.org/10.1109/TGRS.2013.2242082, 2014.

Armitage, T. W. K. and Ridout, A. L.: Arctic sea ice freeboard from AltiKa and comparison with CryoSat-2 and Operation IceBridge, Geophys. Res. Lett., 42, 6724-6731, https://doi.org/10.1002/2015GL064823, 2015.

Boisvert, L. N., Petty, A. A., and Stroeve, J. C.: The Impact of the Extreme Winter 2015/16 Arctic Cyclone on the Barents-Kara Seas, Mon. Weather Rev., 144, 4279-4287, https://doi.org/10.1175/MWR-D-16-0234.1, 2016.

Chelton, D. B., Ries, J. C., Haines, B. J., Fu, L.-L., and Callahan, P. S.: Satellite Altimetry, in: Satellite Altimetry and Earth Sciences: A Handbook of Tecnhinques and Applications, chap. 1, edited by: Fu, L.-L. and Cazenave, A., Academic Press, 2001.

Comiso, J. C.: Large decadal decline of the arctic multiyear ice cover, J. Climate, 25, 1176-1193, https://doi.org/10.1175/JCLID-11-00113.1, 2012.

Comiso, J. C., Cavalieri, D. J., and Markus, T.: Sea ice concentration, ice temperature, and snow depth using AMSR-E data, IEEE T. Geosci. Remote, 41, 243-252, https://doi.org/10.1109/TGRS.2002.808317, 2003.

Connor, L. N., Laxon, S. W., Ridout, A. L., Krabill, W. B., and McAdoo, D. C.: Comparison of Envisat radar and airborne laser altimeter measurements over Arctic sea ice, Remote Sens. Environ., 113, 563-570, https://doi.org/10.1016/j.rse.2008.10.015, 2009.

Giles, K. and Hvidegaard, S.: Comparison of space borne radar altimetry and airborne laser altimetry over sea ice in the Fram Strait, Int. J. Remote Sens., 1161, 37-41, https://doi.org/10.1080/01431160600563273, 2006.

Giles, K. A., Laxon, S. W., Wingham, D. J., Wallis, D. W., Krabill, W. B., Leuschen, C. J., McAdoo, D., Manizade, S. S., and
Raney, R. K.: Combined airborne laser and radar altimeter measurements over the Fram Strait in May 2002, Remote Sens. Environ., 111, 182-194, https://doi.org/10.1016/j.rse.2007.02.037, 2007.

Giles, K. A., Laxon, S. W., and Ridout, A. L.: Circumpolar thinning of Arctic sea ice following the 2007 record ice extent minimum, Geophys. Res. Lett., 35, 2006-2009, https://doi.org/10.1029/2008GL035710, 2008.

Grenfell, T. C. and Maykut, G. A.: The optical properties of ice and snow in the Arctic basin, J. Glaciol., 18, 445-463, 1977.

Guerreiro, K., Fleury, S., Zakharova, E., Rémy, F., and Kouraev, A.: Remote Sensing of Environment Potential for estimation of snow depth on Arctic sea ice from CryoSat-2 and SARAL / AltiKa missions, Remote Sens. Environ., 186, 339-349, https://doi.org/10.1016/j.rse.2016.07.013, 2016.

Guerreiro, K., Fleury, S., Zakharova, E., Kouraev, A., Rémy, F., and Maisongrande, P.: Comparison of CryoSat-2 and ENVISAT radar freeboard over Arctic sea ice: toward an improved Envisat freeboard retrieval, The Cryosphere, 11, 2059-2073, https://doi.org/10.5194/tc-11-2059-2017, 2017.

Kern, S., Khvorostovsky, K., Skourup, H., Rinne, E., Parsakhoo, Z. S., Djepa, V., Wadhams, P., and Sandven, S.: The impact of snow depth, snow density and ice density on sea ice thickness retrieval from satellite radar altimetry: results from the ESA-CCI Sea Ice ECV Project Round Robin Exercise, The Cryosphere, 9, 37-52, https://doi.org/10.5194/tc-9-37-2015, 2015.

Kurtz, N.: IceBridge quick look sea ice freeboard, snow depth, and thickness product manual, Tech. rep., 2014.

Kurtz, N. T. and Farrell, S. L.: Large-scale surveys of snow depth on Arctic sea ice from Operation IceBridge, Geophys. Res. Lett., 38, 1-5, https://doi.org/10.1029/2011GL049216, 2011.

Kurtz, N. T., Farrell, S. L., Studinger, M., Galin, N., Harbeck, J. P., Lindsay, R., Onana, V. D., Panzer, B., and Sonntag, J. G.: Sea ice thickness, freeboard, and snow depth products from Operation IceBridge airborne data, The Cryosphere, 7, 1035-1056, https://doi.org/10.5194/tc-7-1035-2013, 2013.

Kurtz, N. T., Galin, N., and Studinger, M.: An improved CryoSat-2 sea ice freeboard retrieval algorithm through the use of waveform fitting, The Cryosphere, 8, 1217-1237, https://doi.org/10.5194/tc-8-1217-2014, 2014.

Kwok, R.: Simulated effects of a snow layer on retrieval of CryoSat-2 sea ice freeboard, Geophys. Res. Lett., 41, 50145020, https://doi.org/10.1002/2014GL060993, 2014.

Kwok, R. and Cunningham, G. F.: ICESat over Arctic sea ice: Estimation of snow depth and ice thickness, J. Geophys. Res.-Oceans, 113, 1-17, https://doi.org/10.1029/2008JC004753, 2008.

Kwok, R., Cunningham, G. F., Zwally, H. J., and Yi, D.: Ice, Cloud, and land Elevation Satellite (ICESat) over Arctic sea ice: Retrieval of freeboard, J. Geophys. Res.-Oceans, 112, 1-19, https://doi.org/10.1029/2006JC003978, 2007.

Kwok, R., Kurtz, N. T., Brucker, L., Ivanoff, A., Newman, T., Farrell, S. L., King, J., Howell, S., Webster, M. A., Paden, J., Leuschen, C., MacGregor, J. A., Richter-Menge, J., Harbeck, J., and Tschudi, M.: Intercomparison of snow depth retrievals over Arctic sea ice from radar data acquired by Operation IceBridge, The Cryosphere, 11, 2571-2593, https://doi.org/10.5194/tc-112571-2017, 2017. 
Laxon, S., Peacock, N., and Smith, D.: High interannual variability of sea ice thickness in the Arctic region, Nature, 425, 947-950, https://doi.org/10.1038/nature02063.1., 2003.

Laxon, S. W., Giles, K. A., Ridout, A. L., Wingham, D. J., Willatt, R., Cullen, R., Kwok, R., Schweiger, A., Zhang, J., Haas, C., Hendricks, S., Krishfield, R., Kurtz, N., Farrell, S., and Davidson, M.: CryoSat-2 estimates of Arctic sea ice thickness and volume, Geophys. Res. Lett., 40, 732-737, https://doi.org/10.1002/grl.50193, 2013.

Maaß, N., Kaleschke, L., Tian-Kunze, X., and Drusch, M.: Snow thickness retrieval over thick Arctic sea ice using SMOS satellite data, The Cryosphere, 7, 1971-1989, https://doi.org/10.5194/tc7-1971-2013, 2013

Markus, T. and Cavalieri, D. J.: Snow Depth Distribution Over Sea Ice in the Southern Ocean from Satellite Passive Microwave Data, Antar. Res. S., 74, 19-39, https://doi.org/10.1029/AR074p0019, 1998.

Markus, T. and Cavalieri, D. J.: AMSR-E level 3 Sea Ice Products Algorithm Theoretical Basis Document, Tech. rep., NASA Goddard Space Flight Center, 2012.

Maykut, G. A. and Untersteiner, N.: Some results from a timedependent thermodynamic model of sea ice, J. Geophys. Res., 76, 1550-1575, https://doi.org/10.1029/JC076i006p01550, 1971.

Nandan, V., Geldsetzer, T., Yackel, J. J., Islam, T., Gill, J. P. S., and Mahmud, M.: Multifrequency Microwave Backscatter from a Highly Saline Snow Cover on Smooth First-Year Sea Ice: FirstOrder Theoretical Modeling, IEEE T. Geosci. Remote, 55, 21772190, https://doi.org/10.1109/TGRS.2016.2638323, 2017.

Peacock, N. R. and Laxon, S. W.: Sea surface height determination in the Arctic Ocean from ERS altimetry, J. Geophys. Res.-Oceans, 109, 1-14, https://doi.org/10.1029/2001JC001026, 2004.

Powell, D. C., Markus, T., Cavalieri, D. J., Gasiewski, A. J., Klein, M., Maslanik, J. A., Stroeve, J. C., and Sturm, M.: Microwave Signatures of Snow on Sea Ice: Modeling, IEEE T. Geosci. Remote, 44, 3091-3102, https://doi.org/10.1109/TGRS.2006.882139, 2006.

Raney, R. K.: Delay/Doppler radar altimeter for ice sheet monitoring, Igarss, 2, 862-864, 1995.

Rapley, C., Cooper, A. P., Brenner, A. C., and Drewry, D.: A Study of Satellite Radar Altimeter Operations Over Ice-covered Surfaces, Tech. Rep. July 2015, European Space Agency, 1983.

Ricker, R., Hendricks, S., Helm, V., Skourup, H., and Davidson, M.: Sensitivity of CryoSat-2 Arctic sea-ice freeboard and thickness on radar-waveform interpretation, The Cryosphere, 8, 16071622, https://doi.org/10.5194/tc-8-1607-2014, 2014.

Ricker, R., Hendricks, S., Girard-Ardhuin, F., Kaleschke, L., Lique, C., Tian-Kunze, X., Nicolaus, M., and Krumpen, T.: Satellite-observed drop of Arctic sea ice growth in winter 2015-2016, Geophys. Res. Lett., 44, 3236-3245, https://doi.org/10.1002/2016GL072244, 2017.

Ridout, A. and Ivanova, N.: Sea Ice Climate Change Initiative: D2.6 Algorithm Theoretical Basis Document (ATBDv1) Sea Ice Concentration, European Space Agency, 1, 1-41, 2013.
Rinke, A., Maturilli, M., Graham, R. M., Matthes, H., Handorf, D., Cohen, L., Hudson, S. R., and Moore, J. C.: Extreme cyclone events in the Arctic: Wintertime variability and trends, Environ. Res. Lett., 12, 094006, https://doi.org/10.1088/17489326/aa7def, 2017.

Schwegmann, S., Rinne, E., Ricker, R., Hendricks, S., and Helm, V.: About the consistency between Envisat and CryoSat-2 radar freeboard retrieval over Antarctic sea ice, The Cryosphere, 10, 1415-1425, https://doi.org/10.5194/tc-10-1415-2016, 2016.

Stroeve, J. C., Schroder, D., Tsamados, M., and Feltham, D.: Warm winter, thin ice?, The Cryosphere, 12, 1791-1809, https://doi.org/10.5194/tc-12-1791-2018, 2018.

Stroeve, J. C., Serreze, M. C., Fetterer, F., Arbetter, T., Meier, W., Maslanik, J., and Knowles, K.: Tracking the Arctic's shrinking ice cover: Another extreme September minimum in 2004, Geophys. Res. Lett., 32, 1-4, https://doi.org/10.1029/2004GL021810, 2005.

Sturm, M., Holmgren, J., and Perovich, D. K.: Winter snow cover on the sea ice of the Arctic Ocean at the Surface Heat Budget of the Arctic Ocean (SHEBA): Temporal evolution and spatial variability, J. Geophys. Res., 107, 1-17, https://doi.org/10.1029/2000JC000400, 2002.

Tilling, R. L., Ridout, A., and Shepherd, A.: Estimating Arctic sea ice thickness and volume using CryoSat-2 radar altimeter data, Adv. Space Res., 62, 1203-1225, https://doi.org/10.1016/j.asr.2017.10.051, 2018.

Ulaby, F. T., Abdelrazik, M., and Stiles, W. H.: Snowcover Influence on Backscattering from Terrain, IEEE T. Geosci. Remote, GE22, 126-133, https://doi.org/10.1109/TGRS.1984.350604, 1984.

Warren, S., Rigor, I., and Untersteiner, N.: Snow depth on Arctic sea ice, J. Climate, 1814-1829, https://doi.org/10.1175/15200442(1999)012<1814:SDOASI >2.0.CO;2, 1999.

Webster, M. a., Rigor, I. G., Nghiem, S. V., Kurtz, N. T., Farrell, S. L., Perovich, D. K., and Sturm, M.: Interdecadal changes in snow depth on Arctic sea ice, J. Geophys. Res.-Oceans, 53955406, https://doi.org/10.1002/2014JC009985, 2014.

Willatt, R., Laxon, S., Giles, K., Cullen, R., Haas, C., and Helm, V.: Ku-band radar penetration into snow cover on Arctic sea ice using airborne data, Ann. Glaciol., 52, 197-205, https://doi.org/10.3189/172756411795931589, 2011.

Wingham, D. J., Francis, C. R., Baker, S., Bouzinac, C., Brockley, D., Cullen, R., de Chateau-Thierry, P., Laxon, S. W., Mallow, U., Mavrocordatos, C., Phalippou, L., Ratier, G., Rey, L., Rostan, F., Viau, P., and Wallis, D. W.: CryoSat: A mission to determine the fluctuations in Earth's land and marine ice fields, Adv. Space Res., 37, 841-871, 2006.

Yi, D. and Zwally, H. J.: Arctic Sea Ice Freeboard and Thickness, Version 1, Boulder, Colorado USA. NSIDC: National Snow and Ice Data Center, https://doi.org/10.5067/SXJVJ3A2XIZT, 2009 (updated 15 April 2014).

Zygmuntowska, M., Rampal, P., Ivanova, N., and Smedsrud, L. H.: Uncertainties in Arctic sea ice thickness and volume: new estimates and implications for trends, The Cryosphere, 8, 705-720, https://doi.org/10.5194/tc-8-705-2014, 2014. 